\title{
Is Menstruation Still a Dark Side of the Society in 21th \\ Century in Nepal?
}

\section{Kosh Bilash Bagale}

\begin{abstract}
Menstruation is a natural and biological phenomenon, but our patriarchal Nepalese society has practiced different taboos during the menstruation. Due to the taboos, women are deprived of different physical and psychological problems in this period. People are not much discussing the menstrual issues in their home and societies. The aim of this study is to explore the existing practices, prevailing knowledge, source of information and problems facing by girl sat their home and school. In-depth interview was conducted from the purposively selected students from Gongabu Health Post Kathmandu. Collected data were analysed on thematic basis and relevant themes were generated. Study shows that students had a poor knowledge about menarche. Lack of awareness and preparedness most of them used traditional pad during the menstruation and were frightened on their menarche. There are still several taboos about menstruation in different parts of the country and ethnic groups which act for women deprivation to the progress and grip the opportunity.
\end{abstract}

Keywords: menstruation, menarche, taboo, exclude, adolescence

\section{Introduction}

Menstruation is a part of female reproductive cycle that starts when girls become sexually matured at puberty. During a menstrual period, a woman bleeds from her uterus via the vagina which lasts from three to seven days (Hamal \&K.C, 2014).That is a natural phenomenon, all women have to go through but the societal and cultural stigmatization during menstruation often excludes women from services and opportunities. It is unfortunate that even today these natural phenomena are still considered as a taboo in our patriarchal Nepalese society, even in the cities where people are mostly educated. Countries like Nepal where girls have lower literacy rate than boys 57.4 and $75.1 \%$ respectively (CBS, 2011) because of not attending school or dropping school altogether due to lack of clean and safe toilet to change their sanitary pad or towels along with social and religious restrictions while they are menstruating. At that time feminist may claim that masculine do not concentrate the women issue seriously by which they are facing several reproductive problems and deprive for opportunities.

Due to fear of humiliation and discomfort, girls prefer to stay at home rather than going to school. Adolescence is a transitional period from childhood to adult life during which pubertal development and sexual maturation takes place, thus making psychological development challenge adolescents have to face. Menarche is the most significant event in the life of women. During puberty, hormonal, psychological, cognitive and physical changes occur simultaneously 
and interactively making physiological development, social and behavioural dimensions. More than just a physiological process, menstruation may be looked on as restrictions on women's religious and social traditions or as a taboo (Sapkota, et al., 2013).

Menstruation is generally considered unclean in Nepalese society. For most girl's menarche is a negative frightening experience or at the best, a nuisance or is something to fear or to be ashamed of. Boundaries in daily activities avoid entering holy places and dietary restrictions (taboo on consumption of food like curd, milk etc.) during the menstrual period are also imposed. Menstruation and its practices are still clouded by taboos and social-cultural restrictions, resulting in adolescence girls remaining ignorant of the scientific facts, hygiene and health practices, which sometimes result into adverse health outcomes. Our traditional society discourages open discussion to help these issues.

Such significant transition from childhood to womanhood for adolescent girls is further manifested in Nepal through traditional and socio-cultural aspects of menstruation, which is perceived as an impure, bound by silence, shame and social taboos. There is lack of mobility, freedom, and access to normal activities and services.

Although several research studies have done by different researchers about the menstrual hygiene related topic, but there is some gap about how society perceive the women during menstruation and what effect women are facing due to these factors. So, I am interested in fulfilling this gap and select the topic 'Is menstruation still dark side in Nepalese society'?

The aim of this study is to explore the existing practices, prevailing knowledge, source of information, problems faced by girls at home and at school, and how family and community perceive issues of the menstruation. So, completion of this research might contribute in the field of education and reproductive health as well as support the positive change in society about menstrual taboos.

\section{Method}

This research is based on qualitative nature. There are many ways to analyse qualitative data. So, researcher used thematic, descriptive approach or more in-depth methods. There are lots of software developed for analysing the qualitative data (Pope, Sue, \& Nicholas, 2000). Researcher read and reread the transcribed interview several times; highlighting key issues pointed by all respondents and again looked for common and different view they have provided. It enables to formulate core message of the interview and made themes by open coding, axial coding and selective coding.

The issues of study are related to feminism. According to Anderson, "Feminism isn't about making women stronger. Women are already strong. It's about changing the way the world perceives that strength." This theory has created from social theories that are more inclusive and creative than those which assume the actors to always be a man (Crossman, 2019).

Similarly, the concept of this research is based on Health Belief Model (HBM), 
which introduced in the 1950 s by social psychologists (Hochbaum, Rosenstock \& Kegels). HBM assume that people will adopt a healthy behaviour when they feel a negative health condition or has a positive expectation by taking a recommended healthy action. Perceived susceptibility, perceived severity, perceived benefits, and perceived barriers are the four mainconstructs of HBM (Conner \& Norman, 1996).

To apply the Health Belief Model (HBM) in menstruation related fields, when people (women) suspect menstrual related health problems, severity and threats of disease then they are more likely to change their behaviour towards the healthy way i.e. follow preventive measures (like use sanitary pad, taking bath regularly, taking T. D. vaccine, Iron and Folic acid etc). Cues to action may contribute by health education, campaign, government policy and strategy etc change for social taboo like restriction for socio cultural activities and food consumption. For dig out the mystery of menstrual related practices in different communities' researcher also followed the grounded theory during the data collection. Grounded theory originates from sociology, specifically from symbolic interactionism, which posits that meaning is negotiated and understood through interactions with others in social processes (Starks \& Trinidad, 2007).

The adolescence schoolgirls who came to received health services in Gongabu health post Kathmandu and originally from different parts of the country were the population of the study andselected by purposively. Sample size was selected based on saturation of the qualitative data. To fulfilment of the research objective researcher conducted in-depth interview with the adolescent school girls. Before starting the interview developed the rapport and became familiar with respondents. Similarly, researcher considered the ethical norms and maintained confidentiality which helps to disclose about the topic. Collected data was analysed under the different thematic form.

\section{Results and Discussion}

Menstruation is related to fertilization which is controlled by sex hormone like estrogens and progesterone if pregnancy does not occur the thick lining of uterus starts to break down and blood, tissue parts etc flow out of vagina called menstruation or a period. Although it is a natural process, generally our society does not discuss about these issues' consequences women are facing several psycho-social and health problems. During the discussion with Maya, Geeta and Rima (Pseudo name) they expressed various practices and problem (physical, mental, psycho - social, emotional and different taboo etc.) facing by adolescent or women in our society. Women in our society have also dominated by socio - culturally in different field. Bardieu terms symbolic violence with illustrations of how such violence is reproduced in menstrual period in society.

\section{Menstruation is Natural Phenomenon}

As a nature of qualitative research, researcher wants to explore root problem related to menstrual hygiene and taboo. So, to find out actual problem researcher chosen the respondents who were studied in secondary level in Kathmandu and they represent different ethnic groups and different parts of the country and build a rapport with them. During the conversation they 
expressed their feeling and experiences. At first, researcher took interview with Maya she looked some nervous to discuss issues of menstruation, but she maintained herself very soon.

Speaking about physical and biological aspect she had a knowledge about menstruation and said that, 'it is a biological process which occur reproductive age of women'. She has facing some problems during the menstruation like heavy bleeding, loss of appetite, dysmenorrhoea, nausea, vomiting etc. Similarly, when discussed with Geeta, she also said that it is a natural process of women's life. She was from Rai community in eastern Nepal. At the age of 13 she had menarche.

Similarly, Rima is another respondent of the study. She was from Kalikot district. When she was 14 her menarche started. She had also some knowledge about menarche at the time of interview. She was in school at the time of menarche and felt abdominal discomfort with heavy bleeding beyond that she was much frightened about the mystery of menarche. She looks sweated when she expressed her previous feeling. Our society behaves differently and delimited women for several opportunity and several health risk during menstruation. Since it is a natural phenomenon, I argue that we should take it simply and not make it complex issue. But it is necessary to provide scientific knowledge about menstruation related issue for adolescences girls and society.

\section{Menstruation Related Taboos}

As they were studying in secondary level, they had some knowledge about menstruation, but they mentioned that they had very few knowledge at the time of their menarche. Maya said that, "at the age of 12 my menarche was started and that time I had very frightened and weeps". She also said that, "during the menarche my maternal grandmother copes me, she taught me about menstruation like bleeding phase and socio-cultural practices and to follow them strictly".

According to Maya, age might be the factor she had not thought about that. While discussing about the current practices of menstruation in her society, she said that Kathmandu now has no restrictions like her hometown still has. They are still following different practices in her village, like not drinking cow's milk within three days, working in kitchen, keeping distance with religious places, etc. During the conversation, Maya said she use pads that are available in the medical hall, daily bath and mentioned she has no problems about that. But meanwhile in her village they are still using homemade pads from clothes and women of mother generation they don't bath for the first 3 days holding the taboo since it is sinned to break the taboos. They sleep in floor and sometimes outside the house facing problems like rain, snakes and wild animals. She also said that in her village they still follow these taboos thinking menstruation is a critical problem.

In the same issue, Geeta had some knowledge and healthy practices in Kathmandu. But in her community, there were also many taboos. During the period they do not touch temple, fruits plant and water pot. If they did this, their family member may be sick according to the taboo.

They are restricted three days during menstruation and homemade pad are used in that 
time. Bathing practise also is not satisfactory in her community among the elder generation. They commonly took bath on the $3^{\text {rd }}$ and $5^{\text {th }}$ days of menstruation. There are various taboos in our society related to menstruation. During menstruation up to three days blood releases from uterus through vagina, this may produce harmful effect on women's reproductive health as well as urinary health if they do not care about cleanliness. But our practice depends more on tradition, so it is necessary to teach compulsory for all girls either in school curriculum or others informal education about menstrual hygiene which may control UTI and other uterine problem. She was also unknown about menstruation before menarche. At the time of menarche, she was frightened. Her daughter in law conveys her and said "TIMROPHULPHULLEKO". In her Rai community, they said phulphuleko, pudosareko, xuibhayako, yamcibhayako etc. for the menstruation.

Rima, was from Kalikot before three years ago. Her menarche started in school and she drops the class and run for home. She escaped the jungle near the home during the whole day. When sunset she was moved the "CHHAU GHAR" with the help of her mother. She was never seen inside the Chhau Ghar before her menarche. This is narrow, dark, dirty places far from the home. She was frightened and weep, but nobody rescues her from this hut. She was excited to explore like this taboo which was still follow in her hometown. Spent in Chhau Ghar, restricted religious places, not to see male household members, avoid taking milk and milk production, not touch flowers and fruits trees are some deep-rooted taboos in her locality. If somebody ignore the tradition "THULADAUTA" punished them.

Garg and Anand (2015) studied like the same issues in India and showed that, menstrual blood is believed to be dangerous in India and a malevolent person can do harm to a menstruating woman or girl by using black magic ("wisi"). It is also believed that a woman can use her menstrual blood to impose her will on a man. As a $21^{\text {st }}$ century people explore or innovation different unbelievable mysteries and eradicated many fatal diseases on the other hands some parts of the country depriving and dying such types of taboos in country like Nepal and India.

\section{Shyness}

Although, I built a rapport and maintain other confidential when I started the topic of menstruation Maya was shy in the beginning. She said 'MALAAITALAAJLAGXA' and after some time she recovered her position and continued interview. She expressed that, 'our schooling about menstruation is a shameful thing for women. It is not disclosed with other, so we have also deep impact for that.' In the same things Geeta also expressed in her interview. It is a social problem in our society. I never expressed about my period except my mother. Maya memorized her menarche, 'I stayed at classroom in the whole day during my menarche due to the shyness'.

While talking about past events she had problem with, she memorized a situation happened about 2 years ago when she was in her class room her period was started and she had no pads in that time and she felt so awkward that she stayed in her class the whole day because her bench was wet and she was afraid what to do if her teacher asks her questions. (She was 
sweated, and recover slowly...) While the class finished, with the help of her friends she manages to clean her bench. She said, "She may not ever forget that situation in her life". That was the panic memorable situation in her life. I also agree in her statement that most of the women and school girls suffer that kind of problem, so it is necessary to manage the problem in school and home and provide proper education for students as well as parents in society through the informal education and it is also necessary to manage the sanitary pad in school with a free in cost, which may contribute for stop the school dropout and more than that protect their reproductive health. Some Province in Nepal piloting school nurse programme since fiscal year 2076/077 which may enhance all seven province of the country in near future.

But during the discussion Geeta did not feel any hesitation. I think this might be causes of cultural impact. She easily explores the situation which was practices in her (Rai community) hometown. Similarly, Rima who was from that community where peoples highly follows the traditional practices, but now she is not feeling any hesitation to discuss in this topic which may cause by her bitter experiences in the past. She had faced many socio-cultural difficulties in her hometown as a result now she shows the revolutionary characteristics during the interview. She focused that it is necessary to change even any cost or any value.

\section{Socio-cultural aspect}

What type of socio - cultural practice and taboo are there in your society related to menstruation? I asked for Maya, she again memorized her menarche, at the age of 12 she had menarche. That happened in her maternal uncle's home. Her maternal grandmother was very religious person, she said. After menstruation she copes to me, said Maya. "She sympathy me and enter the home. She gave some old cloth for the use of pad". She started to advise me about menstruation, like do not touch anything, stay at room in daytime, do not drink milk, and things like this. I felt bored at that movement and I thought they behaved me like a criminal. She provides me some old dirty cloth (bhutto and gundri) and advised not to touch anything and told me not to let anyone touch my bed, she helped me to bath on the day $3^{\text {rd }}, 5^{\text {th }}$ and $7^{\text {th }}$ in the nearest river at the early morning in too cold water. 'That was very cruel I clearly memorize that'. In our Hindus culture there are many rigid values, which we follow innocently. I strongly disagree to these values she emphasised.

After conversation for those girls and self-experiences from masculine point of view, there are still some cruel socio-cultural taboo which burden the risk for women health. She expressed her feeling continuously, after $7^{\text {th }}$ day my mother came, and we returned our own home. 'That was pleasure for me, she memorized this situation. When she entered the home, her family gave her mirror, comb, ribbon and several new clothes with TIKA and DAKSHINA. She slightly smiled, when she memorized this movement and said that 'our culturehas also values for women,' she forgot her traumatic experiences during menstruation. Equally, in the psychological side she felt sad during her menstruation and wished they never come. She felt frustrated when her society 
restricts everything during this time.

Geeta who came from Rai community said that, 'in the Rai community they did not care outside the home but cared in their own home during menstruation". They don't share menstrual related issue in their community. In their community they were convinced that if somebody shares their menstruation they will be attacked by witch. There were not any taboos for food consumption and cooking. They could sleep in their own bed during menstruation but must stay consciousness towards the GOD. If they faced any problem related to menstruation (like dysmenorrhoea, menstrual disorder, heavy bleeding etc,) they contact with DHAMI first, which might be harmful some time. Rima also expressed their socio-cultural aspect related to menstruation. Her society more traditional and rigid for menstruation with a name of CHHAUPADI. Due to socio cultural taboos some women were died in Chhau Ghar which is very disgraceful for us in $21^{\text {st }}$ centuries.

Most of the adolescent's girls have a good knowledge about menstruation is a natural phenomenon. There are similar taboos related to menstruation all parts of the country, but western parts follow more bit than other. Educated girls have not reflected shyness during discussion about reproductive health. And every ethnic group have different values and practices related to menstruation. But western parts of the country follow more rigid practices in the name of CHHAUPADI.

\section{Conclusion}

In our diversified communities, there are different practices between geographical, ethical, cultural and so on. During the interview all respondents seriously expressed their feeling, experiences and problem which they faced day to day. They expressed, they faced terrible situation during menarche and still facing several menstrual taboos and problems (like restriction to be kitchen and worship room, restriction of food, sleep in floor, avoiding for touching fruits, flowers, lack of sanitary pad, soap and water in school and chhaupadi in western Nepal) at home and schoolin the name of socio- cultural taboos. In my opinion, no women in our communities worship god during menstruation even though they are well academic qualified because they were raise with this taboo. So, it is necessary to perform campaign in societies, so that it will help to change those generations who are more rigid with this issue. The main source of knowledge about menarche and menstruation were mothers and family members of the respondents but themselves may not have a well knowledge about that. Design the well contain school curriculum, advocate and provide the reproductive health education in school and communities which may contribute to change practices and perception related to menstruation in community and transform dark side to bright side with the shifting paradigm in Nepal.

\section{References}

CBS (2011). Report on National Population Census. Kathmandu: Central Bureau of Statistics. Government of Nepal.

Conner, M.\& Norman, P. (1996). Predicting health behaviour. Search and practice with social cognitive models. Open University Press. Ballmore: Buckingham. 
Crossman, A. (2019). Feminist Theory in Sociology. Retrieved from https://www.thoughtco.com/ feminist-theory-3026624

Garg, S., \& Anand, T. (2015). Menstruation related myths in India: strategies for combating it. Retrieved from https://www.ncbi.nlm.nih.gov/pmc/articles/PMC4408698/

Hamal, M., \&K.C, Sushma. (2014). Hygiene, Health Problems and Socio-Cultural Practices: What School Girls Do During Menstruation. Published. School of Health and Allied Sciences, Pokhara University, Nepal.

Pope, c., sue, Z., \& Nicholas, M. (2000). Analysis Qualitative Data. British Medical Journal (BMJ), 320(7227), 114-6. doi:10.1136/bmj.320.7244.1240

Sapkota, D., Sharma, D., Budhathoki, S. S., Khanal, V. K., and Pokharel, H. P. (2013). Knowledge and practice regarding menstruation among school going adolescence of rural Nepal. Journal of Kathmandu Medical College. Vol. 2, No. 3, Issue 5, Jul.-Sep., 2013

Starks, H.S., \& Trinidad, S. B. (2007).Choose Your Method: A Comparison of Phenomenology, Discourse Analysis, and Grounded Theory. Published in: Qualitative Health Research Volume 17 Number 10 December 2007 1372-1380

\section{The Author}

Kosh Bilash Bagale is an Assistant Lecturer at Purkot Kalika Multiple Campus Tanahun. Currently he is a PhD scholar (Health Education) at Graduate School of Education, T. U. His some articles are published in national (online) journals. He is interested in doing research related to public health. 